\title{
Editorial
}

\section{Applications of Internet of Things}

\author{
Chi-Hua Chen ${ }^{1, *}$ (i) and Kuen-Rong Lo ${ }^{2}$ \\ College of Mathematics and Computer Science, Fuzhou University, Fuzhou 350116, China \\ 2 Telecommunication Laboratories, Chunghwa Telecom Co. Ltd., Taoyuan 326, Taiwan; lo@cht.com.tw \\ * Correspondence: chihua0826@gmail.com; Tel.: +886-975292259
}

Received: 17 August 2018; Accepted: 20 August 2018; Published: 22 August 2018

\begin{abstract}
This editorial introduces the special issue entitled "Applications of Internet of Things", of ISPRS International Journal of Geo-Information. Topics covered in this issue include three main parts: (I) intelligent transportation systems (ITS), (II) location-based services (LBS), and (III) sensing techniques and applications. Three papers on ITS are as follows: (1) "Vehicle positioning and speed estimation based on cellular network signals for urban roads," by Lai and Kuo; (2) "A method for traffic congestion clustering judgment based on grey relational analysis," by Zhang et al.; and (3) "Smartphone-based pedestrian's avoidance behavior recognition towards opportunistic road anomaly detection," by Ishikawa and Fujinami. Three papers on LBS are as follows: (1) "A high-efficiency method of mobile positioning based on commercial vehicle operation data," by Chen et al.; (2) "Efficient location privacy-preserving k-anonymity method based on the credible chain," by Wang et al.; and (3) "Proximity-based asynchronous messaging platform for location-based Internet of things service," by gon Jo et al. Two papers on sensing techniques and applications are as follows: (1) "Detection of electronic anklet wearers' groupings throughout telematics monitoring," by Machado et al.; and (2) "Camera coverage estimation based on multistage grid subdivision," by Wang et al.
\end{abstract}

Keywords: internet of things; intelligent transportation systems; location-based services; sensing techniques and applications

\section{Introduction}

In recent years, the techniques of Internet of Things (IoT) and mobile communication have been developed to detect human and environment information (e.g., geo-information [1,2], weather information [3,4], bio-information [5,6], human behaviors [7,8], etc.) for a variety of intelligent services and applications. The three layers in IoT are sensor, networking, and application layers [9-11]. For sensor and networking layers, the rise of mobile technology advancements [12-15] (e.g., wireless sensor networking, Wi-Fi, Bluetooth, smart mobile device, and Long Term Evolution (LTE)) has led to a new wave of machine-to-machine (M2M), machine-to-human (M2H), human-to-human $(\mathrm{H} 2 \mathrm{H})$, and human-to-machine (H2M) communications [16-20]. For the application layer, several IoT applications, which include energy [21,22], enterprise [23,24], healthcare [25,26], public services [27,28], residency [29,30], retail [31,32], and transportation [33,34], have been designed and implemented to detect environmental changes and send instant updates to a cloud computing server farm via mobile communications and middleware for big geo-data analyzes [35,36]. For instance, on-board units in cars can instantly detect and share information about the geolocation of the car, speed, following distance, and gaps with other neighboring cars [37-40]. While the area of IoT applications and mobile communication is a rapidly expanding field of scientific research, several open research questions still need to be discussed and studied. Therefore, the aim of this special issue is to introduce the readers a number of papers on various aspects of IoT applications. 
This special issue has received a total of 23 submitted papers with only 8 papers [41-48] accepted. A high rejection rate of $65.21 \%$ of this issue from the review process is to ensure that high-quality papers with significant results are selected and published. The statistics of the special issue is presented as follows:

- $\quad$ Submissions (23);

- Publications (8);

- Rejections (15).

The distribution of authors' country is showed as follows:

- China (5);

- Korea (2);

- $\quad$ Brazil (1);

- Chile (1);

- Japan (1);

- $\quad$ Spain (1).

Topics covered in this issue include three main parts: (1) intelligent transportation systems (ITS), (2) location-based services (LBS), and (3) sensing techniques and applications. The three topics and accepted papers are briefly described below.

\section{Intelligent Transportation Systems}

Three papers on ITS are as follows: (1) "Vehicle positioning and speed estimation based on cellular network signals for urban roads," by Lai and Kuo [41]; (2) "A method for traffic congestion clustering judgment based on grey relational analysis," by Zhang et al. [42]; and (3) "Smartphone-based pedestrian's avoidance behavior recognition towards opportunistic road anomaly detection," by Ishikawa and Fujinami [43].

Lai and Kuo from China in "Vehicle positioning and speed estimation based on cellular network signals for urban roads" proposed a vehicle positioning method and a speed estimation method to analyze the cell IDs, cell sequences, and the cell dwell time of connected cells from cellular floating vehicle data (CFVD). The cell sequences can be considered to support the analysis of the judgment of urban road direction, and the cell dwell time of connected cells can be considered to support the analysis of the discrimination of proximal urban roads. The location and vehicle speed can be estimated by the k-nearest neighbor algorithm in accordance with the CFVD. In experimental environments, six urban road segments in Kaohsiung and Pingtung in Taiwan were driven in 27 runs for the evaluation of the proposed methods, and the results showed that the accuracies of vehicle positioning and speed estimation were $100 \%$ and $83.81 \%$, respectively [41].

Zhang et al. from China and Chile in "A method for traffic congestion clustering judgment based on grey relational analysis" proposed a grey relational membership degree rank clustering algorithm based on a grey relational clustering model to analyze the traffic information (e.g., traffic flow velocity, traffic flow density and traffic volume) for the detection of traffic congestion. The proposed method based on grey relational analysis can obtain the membership degree rank of classes for judging the rank of data objects and improving the accuracy of traffic congestion detection. In experimental environments, the practical traffic flow records were collected from 30 drivers to evaluate the proposed method, and the results showed that the average accuracy of the proposed algorithm was $24.9 \%$ higher than that of the K-means algorithm [42].

Ishikawa and Fujinami from Japan in "Smartphone-based pedestrian's avoidance behavior recognition towards opportunistic road anomaly detection" used a random forest method as the classifier to analyze the azimuth patterns from smartphones for the detection of pedestrians' avoidance behaviors, and the road anomalies can be detected in accordance with the pedestrians' avoidance behaviors. In experimental environments, the practical pedestrians' avoidance behaviors were collected 
from 7 males and 2 females to evaluate the proposed method, and the results showed that the average accuracy of the proposed method was higher than that of other methods [43].

\section{Location-Based Services}

Three papers on LBS are as follows: (1) "A high-efficiency method of mobile positioning based on commercial vehicle operation data," by Chen et al. [44]; (2) "Efficient location privacy-preserving k-anonymity method based on the credible chain," by Wang et al. [45]; and (3) "Proximity-based asynchronous messaging platform for location-based Internet of things service," by gon Jo et al. [46].

Chen et al. from China in "A high-efficiency method of mobile positioning based on commercial vehicle operation data" proposed a mobile positioning method to analyze the information of global positioning system (GPS) and cellular network signals from commercial vehicle operation data for estimating the location of each cell-RSSI (received signal strength indication) pair in training stage. In the runtime stage, the trained location of each cell-RSSI pair was used to estimate the location of the vehicle in accordance with the information of cell and RSSI for mobile positioning. In experimental environments, 6,571,550 practical commercial vehicle operation records were collected to evaluate the proposed method, and the results showed that the average location error of the proposed method was lower than cell ID-based method [44].

Wang et al. from China in "Efficient location privacy-preserving k-anonymity method based on the credible chain" analyzed the user's environment and social attributes to determine the optimal $k$ value for a k-anonymous location privacy protection method, and the $k$ location nodes were contained in a fake trajectory which can be generated based on the credible chain. In experimental environments, numerical analysis and simulations were given to evaluate the proposed method, and the results showed that the service accuracy of the proposed method was 100\% [45].

Gon Jo et al. from Korea in "Proximity-based asynchronous messaging platform for location-based Internet of things service" proposed a distance-based asynchronous messaging platform based on a location-based message-delivery protocol. The proposed platform and protocol can be used to disperse traffic and improve stability. In experimental environments, the proposed platform and protocol were implemented to analyze the transmission time and response time for the verification of obtaining location-based messaging [46].

\section{Sensing Techniques and Applications}

Two papers on sensing techniques and applications are as follows: (1) "Detection of electronic anklet wearers' groupings throughout telematics monitoring," by Machado et al. [47]; and (2) "Camera coverage estimation based on multistage grid subdivision," by Wang et al. [48].

Machado et al. from Brazil, Spain and Korea in "Detection of electronic anklet wearers' groupings throughout telematics monitoring" proposed sensor data fusion algorithms to analyze the data from anklet positioning devices for tracking convicted individuals. The proposed algorithms can collect and analyze the information of timestamps and locations to estimate the risk assessment. In experimental environments, 10,000 simulated devices generated a set of paths which were obtained from GPS module to evaluate the proposed method, and the response time of the proposed algorithms was evaluated to demo the practicality of the proposed algorithm [47].

Wang et al. from China in "Camera coverage estimation based on multistage grid subdivision" proposed a method based on multistage grid subdivision to efficiently estimate superior camera coverage. This study defined 16 codes of grids, and the grid can be subdivided until each grid can be covered as one of these codes. In experimental environments, the practical data from 15 cameras were collected to evaluate the proposed method, and the results showed that the camera coverage can be estimated by the proposed method with lower time consumption [48].

Author Contributions: C.-H.C. and K.-R.L. edited the special issue, entitled "Applications of Internet of Things", of ISPRS International Journal of Geo-Information. C.-H.C. and K.-R.L. wrote this editorial for the introduction of the special issue. 
Funding: This research received no external funding.

Acknowledgments: We would like to thank all authors who submitted their valuable papers to the special issue, entitled "Applications of Internet of Things", of ISPRS International Journal of Geo-Information. Furthermore, we would like to thank all reviewers and the editorial team of ISPRS International Journal of Geo-Information for their great efforts and supports.

Conflicts of Interest: The authors declare no conflict of interest.

\section{References}

1. Lin, Y.B.; Lin, Y.W.; Hsiao, C.Y.; Wang, S.Y. Location-based IoT applications on campus: The IoTtalk approach. Pervasive Mob. Comput. 2017, 40, 660-673. [CrossRef]

2. Chen, C.H.; Lee, C.A.; Lo, C.C. Vehicle localization and velocity estimation based on mobile phone sensing. IEEE Access 2016, 4, 803-817. [CrossRef]

3. Wu, S.M.; Chen, T.; Wu, Y.J.; Lytras, M. Smart cities in Taiwan: A perspective on big data applications. Sustainability 2018, 10, 106. [CrossRef]

4. Kung, H.Y.; Kuo, T.H.; Chen, C.H.; Tsai, P.Y. Accuracy analysis mechanism for agriculture data using the ensemble neural network method. Sustainability 2016, 8, 735. [CrossRef]

5. $\mathrm{Ku}, \mathrm{H} . \mathrm{H}$. Design of a golf swing injury detection and evaluation open service platform with ontology-oriented clustering case-based reasoning mechanism. Technol. Health Care 2015, 24, S261-S270. [CrossRef] [PubMed]

6. Marques, G.; Ferreira, C.R.; Pitarma, R. A system based on the Internet of things for real-time particle monitoring in buildings. Int. J. Environ. Res. Public Health 2018, 15, 821. [CrossRef] [PubMed]

7. Banos, O.; Villalonga, C.; Bang, J.; Hur, T.; Kang, D.; Park, S.; Huynh-The, T.; Le-Ba, V.; Amin, M.B.; Razzaq, M.A.; et al. Human behavior analysis by means of multimodal context mining. Sensors 2016, 16, 1264. [CrossRef] [PubMed]

8. Lo, C.L.; Chen, C.H.; Kuan, T.S.; Lo, K.R.; Cho, H.J. Fuel consumption estimation system and method with lower cost. Symmetry 2017, 9, 105. [CrossRef]

9. Lin, J.; Yu, W.; Zhang, N.; Yang, X.; Zhang, H.; Zhao, W. A survey on Internet of things: Architecture, enabling technologies, security and privacy, and applications. IEEE Internet Things J. 2017, 4, 1125-1142. [CrossRef]

10. Razzaque, M.A.; Milojevic-Jevric, M.; Palade, A.; Clarke, S. Middleware for Internet of things: A survey. IEEE Internet Things J. 2016, 3, 70-95. [CrossRef]

11. Ruiz-Rosero, J.; Ramirez-Gonzalez, G.; Williams, J.M.; Liu, H.; Khanna, R.; Pisharody, G. Internet of things: A scientometric review. Symmetry 2017, 9, 301. [CrossRef]

12. Lin, Y.W.; Lin, Y.B.; Hsiao, C.Y.; Wang, Y.Y. IoTtalk-RC: Sensors as universal remote control for aftermarket home appliances. IEEE Internet Things J. 2017, 4, 1104-1112. [CrossRef]

13. Lin, Y.B.; Wang, S.Y.; Huang, C.C.; Wu, C.M. The SDN approach for the aggregation/disaggregation of sensor data. Sensors 2018, 18, 2025. [CrossRef] [PubMed]

14. Lin, Y.B.; Cheng, H.Y.; Cheng, Y.H.; Agrawal, P. Implementing automatic location update for follow-me database using VoIP and Bluetooth technologies. IEEE Trans. Comput. 2002, 51, 1154-1168. [CrossRef]

15. Liou, R.H.; Lin, Y.B.; Sung, Y.C.; Liu, P.C.; Wietfeld, C. Performance of CS fallback for long term evolution mobile network. IEEE Trans. Veh. Technol. 2014, 63, 3977-3984. [CrossRef]

16. Aijaz, A.; Aghvami, A.H. Cognitive machine-to-machine communications for Internet-of-things: A protocol stack perspective. IEEE Internet Things J. 2015, 2, 103-112. [CrossRef]

17. Pang, Y.C.; Lin, G.Y.; Wei, H.Y. Context-aware dynamic resource allocation for cellular M2M communications. IEEE Internet Things J. 2016, 3, 318-326. [CrossRef]

18. Gao, Y.; Qin, Z.; Feng, Z.; Zhang, Q.; Holland, O.; Dohler, M. Scalable and reliable IoT enabled by dynamic spectrum management for M2M in LTE-A. IEEE Internet Things J. 2016, 3, 1135-1145. [CrossRef]

19. Yin, S.; Bao, J.; Zhang, Y.; Huang, X. M2M security technology of CPS based on Blockchains. Symmetry 2017, 9, 193. [CrossRef]

20. Jang, U.; Lim, H.; Kim, H. Privacy-Enhancing Security Protocol in LTE Initial Attack. Symmetry 2014, 6, 1011-1025. [CrossRef]

21. Lin, Y.B.; Wang, L.C.; Chen, W.C. eSES: Enhanced simple energy saving for LTE HeNBs. IEEE Commun. Lett. 2017, 21, 2520-2523. [CrossRef] 
22. Duangmanee, P.; Uthansakul, P. Clock-frequency switching technique for energy saving of microcontroller unit (MCU)-based sensor node. Energies 2018, 11, 1194. [CrossRef]

23. Chiang, M.; Zhang, T. Fog and IoT: An overview of research opportunities. IEEE Internet Things J. 2016, 3 , 854-864. [CrossRef]

24. Lee, S.; Jeong, T. Cloud-based parameter-driven statistical services and resource allocation in a heterogeneous platform on enterprise environment. Symmetry 2016, 8, 103. [CrossRef]

25. Lo, C.C.; Chen, C.H.; Cheng, D.Y.; Kung, H.Y. Ubiquitous healthcare service system with context-awareness capability: Design and implementation. Expert Syst. Appl. 2011, 38, 4416-4436. [CrossRef]

26. Nieuwenhuijsen, M.J.; Donaire-Gonzalez, D.; Foraster, M.; Martinez, D.; Cisneros, A. Using personal sensors to assess the exposome and acute health effects. Int. J. Environ. Res. Public Health 2014, 11, 7805-7819. [CrossRef] [PubMed]

27. Kung, H.Y.; Chen, C.H.; Ku, H.H. Designing intelligent disaster prediction models and systems for debris-flow disasters in Taiwan. Expert Syst. Appl. 2012, 39, 5838-5856. [CrossRef]

28. Chen, C.H.; Wu, C.L.; Lo, C.C.; Hwang, F.J. An augmented reality question answering system based on ensemble neural networks. IEEE Access 2017, 5, 17425-17435. [CrossRef]

29. Zanella, A.; Bui, N.; Castellani, A.; Vangelista, L.; Zorzi, M. Internet of things for smart cities. IEEE Internet Things J. 2014, 1, 22-32. [CrossRef]

30. Kim, S.; Lim, H. Reinforcement learning based energy management algorithm for smart energy buildings. Energies 2018, 11, 2010. [CrossRef]

31. Lin, C.Y.; Wang, L.C.; Tsai, K.H. Hybrid Real-Time Matrix Factorization for Implicit Feedback Recommendation Systems. IEEE Access 2018, 6, 21369-21380. [CrossRef]

32. Lo, C.C.; Kuo, T.H.; Kung, H.Y.; Kao, H.T.; Chen, C.H.; Wu, C.I.; Cheng, D.Y. Mobile merchandise evaluation service using novel information retrieval and image recognition technology. Comput. Commun. 2011, 34, 120-128. [CrossRef]

33. Chen, C.H. An arrival time prediction method for bus system. IEEE Internet Things J. Early Access 2018. [CrossRef]

34. Lai, W.K.; Kuo, T.H.; Chen, C.H. Vehicle speed estimation and forecasting methods based on cellular floating vehicle data. Appl. Sci. 2016, 6, 47. [CrossRef]

35. Lin, Y.B.; Lin, Y.W.; Huang, C.M.; Chih, C.Y.; Lin, P. IoTtalk: A management platform for reconfigurable sensor devices. IEEE Internet Things J. 2017, 4, 1552-1562. [CrossRef]

36. Chen, C.H.; Lin, H.F.; Chang, H.C.; Ho, P.H.; Lo, C.C. An analytical framework of a deployment strategy for cloud computing services: A case study of academic websites. Math. Probl. Eng. 2013, 2013, 384305. [CrossRef]

37. Lu, N.; Cheng, N.; Zhang, N.; Shen, X.; Mark, J.W. Connected vehicles: Solutions and challenges. IEEE Internet Things J. 2014, 1, 289-299. [CrossRef]

38. Cui, J.; Wen, J.; Han, S.; Zhong, H. Efficient privacy-preserving scheme for real-time location data in vehicular ad-hoc network. IEEE Internet Things J. Early Access 2018. [CrossRef]

39. Chen, C.H.; Yang, Y.T.; Chang, C.S.; Hsieh, C.M.; Kuan, T.S.; Lo, K.R. The design and implementation of a garbage truck fleet management system. S. Afr. J. Ind. Eng. 2016, 27, 32-46. [CrossRef]

40. Wu, C.I.; Chen, C.H.; Lin, B.Y.; Lo, C.C. Traffic information estimation methods from handover events. J. Test. Eval. 2016, 44, 656-664. [CrossRef]

41. Lai, W.K.; Kuo, T.H. Vehicle positioning and speed estimation based on cellular network signals for urban roads. ISPRS Int. J. Geo-Inf. 2016, 5, 181. [CrossRef]

42. Zhang, Y.; Ye, N.; Wang, R.; Malekian, R. A method for traffic congestion clustering judgment based on grey relational analysis. ISPRS Int. J. Geo-Inf. 2016, 5, 71. [CrossRef]

43. Ishikawa, T.; Fujinami, K. Smartphone-based pedestrian's avoidance behavior recognition towards opportunistic road anomaly detection. ISPRS Int. J. Geo-Inf. 2016, 5, 182. [CrossRef]

44. Chen, C.H.; Lin, J.H.; Kuan, T.S.; Lo, K.R. A high-efficiency method of mobile positioning based on commercial vehicle operation data. ISPRS Int. J. Geo-Inf. 2016, 5, 82. [CrossRef]

45. Wang, H.; Huang, H.; Qin, Y.; Wang, Y.; Wu, M. Efficient location privacy-preserving k-anonymity method based on the credible chain. ISPRS Int. J. Geo-Inf. 2017, 6, 163. [CrossRef]

46. Gon Jo, H.; Son, T.Y.; Jeong, S.Y.; Kang, S.J. Proximity-based asynchronous messaging platform for location-based Internet of things service. ISPRS Int. J. Geo-Inf. 2016, 5, 116. [CrossRef] 
47. Machado, P.L.; de Sousa, R.T.; de Oliveira Albuquerque, R.; Villalba, L.J.G.; Kim, T.H. Detection of electronic anklet wearers' groupings throughout telematics monitoring. ISPRS Int. J. Geo-Inf. 2017, 6, 31. [CrossRef]

48. Wang, M.; Liu, X.; Zhang, Y.; Wang, Z. Camera coverage estimation based on multistage grid subdivision. ISPRS Int. J. Geo-Inf. 2017, 6, 110. [CrossRef]

(C) 2018 by the authors. Licensee MDPI, Basel, Switzerland. This article is an open access article distributed under the terms and conditions of the Creative Commons Attribution (CC BY) license (http:/ / creativecommons.org/licenses/by/4.0/). 